\title{
PREFACE
}

The principal aim of this dictionary is to provide a convenient reference work for the English-speaking student of Thai. Existing Thai-English dictionaries--at least those prepared within the last two decades--are invariably geared to meet the needs of the Thai-speaking student of English, since that is the market they are intended to reach. But such dictionaries fail in certain crucial respects to satisfy the legitimate needs of the American student. In particular it has been noticed that: (1) They fail to provide a scientifically accurate and up-to-date guide to the pronunciation of Thai words. (2) They neglect to distinguish important levels of usage, e.g., vulgar, common, elegant, colloquial, literary, etc., which are well known to Thai speakers but are impossible for the culturally-unoriented American student to figure out.

(3) They lack many important idioms, compounds, and other specialized combinations of words. (4) Examples, when given, are more likely to be chosen to clarify the peculiarities of English than those of Thai.

The present dictionary contains the following types of information with each of its entries: (1) The traditional Thai spelling as shown in the official Thai monolingual dictionary (the Thai Ministry of Education, Bangkok, 1950). (2) A carefully worked out phonemic transcription using Roman letters. (3) An abbreviation designating the word class, where pertinent. (4) The level of usage, both social and technical, where pertinent. (5) The English definition or equivalent. (6) Many synonyms and antonyms. (7) Examples showing a variety of uses, when the definition alone is insufficient. The dictionary also contains some special kinds of entries which a re missing from many dictionaries. Among these are: (1) Most of the common place names of Thailand, including abbreviated and colloquial (but not dialectal) place names and also most of the common foreign place names likely to be found in newspapers. (2) Common abbreviations of titles, organizations, dates, and the like that are frequently encountered in newspapers.

Although this dictionary has been prepared especially to meet the needs of the American student who wishes to read Thai newspapers and other Thai source materials, the Thai student of English will also find much useful information in this dictionary. The reason for this is that we have tried very hard to find the best and most natural English translation for as many words as possible. The numerous subentries and examples will also often be of interest to the Thai student as well as the American student.

The Thai-English Student's Dictionary is one of two dictionaries being compiled at present by those engaged in work on the Thai Dictionary Project. The other, larger dictionary will be entitled Modern Thai-English Dictionary. Materials for the master file have been gleaned from the context of modern periodicals, newspapers, government reports, and advanced textbooks on literature, history, and the sciences. Idiomatic and colloquial usages have been collected 
from novels and short stories and from examples supplied by educated native speakers. The Student's Dictionary contains selected items from the master file. Particular attention has been paid to items likely to be found in standard prose source materials, including the daily newspapers. The foundations of analysis and description of Thai that a re needed for the compilation of a dictionary were worked out by the editor during the course of many years of research. The special needs of American students have become familiar through several years (1947-60) of teaching Thai in the Department of Oriental Languages, University of California, Berkeley. Since 1953 teaching duties have been primarily devoted to courses in general linguistics in the Department of Linguistics, but from time to time Thai has been used as a demonstration language in a field methods course. In 1956-57 the problems of intonation at terminal points and of stress within the rhythm group were given special emphasis in such a course.

All of the assistants aided materially in the compilation of the Student's Dictionary, though mostly at different stages of the work and for differing periods of time. The responsibility of combing the master files to find the selections they considered important was assumed in succession, by Dr. Soren C. Egerod (now of the University of Copenhagen), Dr. Waiwit Buddhari (now of Chulalongkorn University), and Dr. Ruchira Chinnapongse Mendiones. Dr. Buddhari and Dr. Mendiones have also provided many illustrative examples and have served as models for the normal pronunciation or pronunciations shown in romanized phonemic transcription included with each entry. Dr. Mendiones has further served as consultant in regard to many definitions and has assisted in the overall editing. Mr. George V. Grekoff (now of the University of Washington) carried out instructions for maintaining overall consistency in editing and for the cross checking of references, in so far as there was time for this. He also cooperated in working out details of format and layout and undertook the first proofreading as the offset typing proceeded up to August, 1962. Since then the cross checking and proofreading have been done by Mr. Joseph R. Cooke. The writing of all of the front matter, many grammatical comments, notes, and definitions, and finally another overall proof reading fell to the editor.

The extensive master file could not have been accumulated without the assistance of a great many educated speakers of Thai. In particular we wish to express our indebtedness to the following: Miss Boonchom Chaikosi, Mr. Banvech Chantrasmi, Dr. Vichien Diloksambandh, Dr. Phaitoon Ingkasuwan, Mr. Niphon Kantasewi, M. R. W. Sobhak Kasemsanta, Miss Pensri Kiangsiri, Miss Punnee Kiangsiri, Mr. Ratana Oonyawongse, Dr. Kaw Swasdi Panish, Mr. Chamnan Pradithavanis, Mr. Somprasongk Prathnadi, Mr. Suchat Pusavat, Miss Krisna Tantranon, and Miss Charuwan Thirawat. A number of linguistics research assistants also assisted materially in the compilation of the master files, especially at all levels of the cross-referencing process, including the typing of phonetics and English onto slips and also in proofreading and filing the slips as they were typed. Those who helped in this capacity at different times are Dr. Roy A. Miller (now of Yale University), Dr. David DeCamp (now of the University of Texas), Dr. Karl V. Teeter (now of Harvard University), Dr. Wick R. Miller (now of the University of Utah), and Dr. Catherine A. Callaghan. Of especially great importance has been the excellent 
work of two Thai typists, Mrs. Sarapee Oonyawongse, who typed many thousands of slips for the master file, and Mrs. Boonsiri Donom, who continued the typing of slips and also typed the prefinal manuscript and the offset copy for the present dictionary.

The Thai Dictionary Project was begun in 1951 under the auspices of the Institute of East Asiatic Studies (since 1955 subsumed under the Institute of International Studies) of the University of California, Berkeley. Up until June 15, 1960, most of the funds for the support of this research came out of the research funds of the Institute. In 1956-57, and again in 1958-59, the American Council of Learned Societies provided two grants specifically earmarked for work on the Student's Dictionary. Since June 15, 1960, the continuing work on both dictionaries has been provided for under a government contract (U.S. Office of Education, Language Development, Department of Health, Education, and Welfare). An IBM Executive typewriter with Heritage type was especially selected to blend with the only available IBM Thai typewriter. The typewriters were purchased during the time the Project was being supported by the Institute. The editor and her assistants acknowledge the various kinds of financial aid and assistance from all of these quarters with deep gratitude.

M. R. H.

September, 1963.

Berkeley, California.

\section{PREFACE TO THE SECOND PRINTING}

We have taken the occasion of the second printing to remove a few errors that have been discovered by us or brought to our attention by friends. The corrections cover the page references in the introductory sections as well as a few mistakes in cross reference, spelling, or transcription scattered throughout the volume. Owners of copies of the first printing are reminded that most of the corrections are minor or easily detectable by the user. The only exception is that กฎ was misspelled everywhere as กฏ. This correction has been made on p. 2, col. I, 1. 36 and in the following subentries together with their cross references throughout the book.

M. R. H.

September, 1964.

Berkeley, California. 
